\title{
Profil kandidosis intertriginosa di Poliklinik Kulit dan Kelamin RSUP Prof. Dr. R. D. Kandou Manado periode Januari - Desember 2013
}

\author{
${ }^{1}$ Saranita V. G. Polii \\ ${ }^{2}$ Herry E.J. Pandaleke \\ ${ }^{2}$ Marlyn G. Kapantow \\ ${ }^{1}$ Kandidat Skripsi Fakultas Kedokteran Universitas Sam Ratulangi Manado \\ ${ }^{2}$ Bagian/SMF Kulit dan Kelamin RSUP Prof. Dr. R. D. Kandou Manado \\ Email: saranitavgpolii@ymail.com
}

\begin{abstract}
Intertriginous candidosis is a fungal infection of the skin caused by Candida, especially Candida albicans, in the skin fold areas. This study was aimed to obtain the profile of intertriginous candidosis at Dermatovenereology clinic of Prof. Dr. R. D. Kandou Hospital Manado from January 2013 to December 2013. This was a descriptive retrospective study using medical record data of new and old patients diagnosed as intertriginous candidosis based on number of cases, age group, sex, occupation, location, precipitating factors, and type of treatment. The results showed that of the 4099 total patients there were 40 patients $(0.98 \%)$ with intertriginous candidosis. It is most common in females (70\%), aged 45-64 years $(42.5 \%)$, worked as civilized employee $(32.5 \%)$, location on the groin $(32.43 \%)$, precipitating factor sweaty/damp environment (32.5\%), and topical antifungal (65\%).
\end{abstract}

Keywords: intertriginous candidosis

\begin{abstract}
Abstrak: Kandidosis intertriginosa adalah infeksi jamur kulit yang disebabkan oleh jamur Candida, cenderung oleh spesies Candida albicans pada daerah-daerah lipatan kulit. Penelitian ini bertujuan untuk mengetahui profil kandidosis intertriginosa di Poliklinik Kulit dan Kelamin RSUP Prof. Dr. R. D. Kandou Manado periode Januari 2013 - Desember 2013. Jenis penelitian ialah deskriptif retrospektif menggunakan data rekam medik pasien baru dan lama dengan diagnosis kandidosis intertriginosa yang berobat di Poliklinik Kulit dan Kelamin RSUP Prof. Dr. R. D. Kandou Manado periode Januari 2013 - Desember 2013 berdasarkan jumlah kasus, kelompok usia, jenis kelamin, pekerjaan, lokasi, faktor pencetus, dan jenis pengobatan. Hasil penelitian menunjukkan bahwa terdapat 40 pasien $(0,98 \%)$ kandidosis intertriginosa dari keseluruhan total 4099 pasien. Persentase tertinggi ditemukan pada perempuan (70\%), kelompok usia 45-64 tahun (42,5\%), pekerjaan pasien PNS (32,5\%), lokasi lipatan kulit pada lipat paha $(32,43 \%)$, faktor pencetus berkeringat/lingkungan lembab $(32,5 \%)$, dan terapi antifungi topikal (65\%).
\end{abstract}

Kata kunci: kandidosis intertriginosa

Candida albicans merupakan spesies yang tergolong dalam genus Candida. Jamur Candida hidup dalam tubuh manusia sebagai saprofit yang bisa tinggal dalam alat pencernaan, alat pernapasan, dan vagina orang normal atau sehat, namun dalam keadaan-keadaan tertentu jamur Candida dapat berubah menjadi patogen yang menyebabkan penyakit kandidiasis atau kandidosis. ${ }^{1,2}$ Cara Candida menginfeksi yaitu secara eksogen dan endogen, dan daerah yang paling sering diinfeksi yaitu pada area mukokutan, anus, vagina, dan saluran pencernaan. ${ }^{2}$ 
Kandidosis menyerang semua umur juga baik laki-laki maupun perempuan dan memiliki gambaran klinis yang bermacammacam. ${ }^{1}$ Conant et al. (1971) mengelompokkan klasifikasi kandidosis berdasarkan tempat terkenanya sebagai kandidosis selaput lendir, kandidosis kutis, dan kandidosis sistemik. ${ }^{1}$

Daerah-daerah yang dapat terinfeksi pada kandidosis intertriginosa yaitu lipatanlipatan kulit, antara lain lipat paha, lipat payudara, lipat perut, ketiak, glans penis, serta jari-jari tangan dan jari-jari kaki. ${ }^{1,2}$

Faktor-faktor yang dapat memicu terjadinya infeksi Candida pada kandidosis intertriginosa antara lain pemakaian steroid sistemik maupun topikal, penurunan imunitas karena berbagai sebab (misalnya, limfoma, AIDS), pemakaian antibiotik spektrum luas, diabetes melitus, aposisi daerah-daerah kulit yang menghasilkan lingkungan yang lembab, dan obesitas. ${ }^{3}$

Di Jepang, dilaporkan bahwa kandidosis kutis terdapat pada 755 kasus dari 72.660 pasien yang keluar dari RS, dimana kandidosis intertriginosa merupakan kasus yang paling sering yaitu 347 kasus $(45,96 \%) .{ }^{4}$ Penelitian di suatu provinsi di Irak menunjukkan persentase kandidosis kutis sebanyak 26,2\% dari keseluruhan infeksi jamur kulit. Secara signifikan, distribusi kandidosis intertriginosa menunjukkan persentase $62,9 \%$ dibanding bagian kulit lainnya dan bila dihubungkan dengan jenis kelamin, wanita (64\%) terbanyak menderita kandidosis intertriginosa. ${ }^{5}$ Penelitian yang dilakukan Wowor et al. ${ }^{6}$ di Poliklinik Kulit dan Kelamin RSUP Prof. Dr. R. D. Kandou periode Januari-Desember 2012 melaporkan bahwa terdapat 37 pasien $(3,37 \%)$ kandidosis intertriginosa dari 1096 pasien baru.

Berdasarkan latar belakang diatas, dapat disimpulkan bahwa kandidosis kutis merupakan infeksi jamur kulit yang paling sering ditemukan dengan persentase kasus tertinggi pada kandidosis intertriginosa., Penelitian ini bertujuan untuk mendapatkan profil kandidosis intertriginosa di Poliklinik Kulit dan Kelamin Prof. Dr. R. D. Kandou.

\section{METODE PENELITIAN}

Jenis penelitian ialah deskriptif retrospektif yang dilakukan di Instalasi Rekam Medik serta Poliklinik Kulit dan Kelamin RSUP Prof. Dr. R. D. Kandou Manado. Penelitian ini dilakukan dari bulan November - Desember 2015.

Populasi mencakup seluruh data pasien baru dan lama yang telah berobat di Poliklinik Kulit dan Kelamin RSUP Prof. Dr. R. D. Kandou Manado periode JanuariDesember 2013. Sampel penelitian yaitu seluruh data pasien yang didiagnosis kandidosis intertriginosa di Poliklinik Kulit dan Kelamin RSUP Prof. Dr. R. D. Kandou Manado dalam periode tersebut. Variabel penelitian yang diambil ialah usia, jenis kelamin, pekerjaan, lokasi, faktor pencetus, dan jenis pengobatan.

\section{HASIL PENELITIAN}

Penelitian ini dilakukan pada penderita dengan diagnosis kandidosis intertriginosa di Instalasi Rekam Medik dan Poliklinik RSUP Prof. Dr. R. D. Kandou Manado periode Januari sampai dengan Desember 2013.Terdapat 40 pasien yang didiagnosis kandidosis intertriginosa dari 4099 total pasien dengan persentase sebesar $0,98 \%$.

Tabel 1 menunjukkan kasus kandidosis intertriginosa lebih sering pada perempuan yaitu 28 dari 40 kasus (70\%), sedangkan pada laki-laki terdapat 12 kasus $(30 \%)$.

Tabel 1. Distribusi kandidosis intertriginosa menurut jenis kelamin

\begin{tabular}{ccc}
\hline Jenis kelamin & Jumlah & \% \\
\hline Laki-laki & 12 & 30 \\
Perempuan & 28 & 70 \\
Total & 40 & 100 \\
\hline
\end{tabular}

Tabel 2 menunjukkan kelompok usia 45-64 tahun merupakan yang paling sering menderita kandidosis intertriginosa dengan jumlah 17 orang $(42,5 \%)$, diikuti oleh kelompok usia $\geq 65$ tahun $(27,5 \%)$.

Tabel 3 menunjukkan pekerjaan pasien terbanyak yaitu PNS sejumlah 13 pasien $(32,5 \%)$ diikuti IRT (25\%). Pada keterangan tidak bekerja, 1 dari 2 pasien tersebut yaitu bayi dengan usia $<1$ tahun. 
Tabel 2. Distribusi kandidosis intertriginosa menurut kelompok umur

\begin{tabular}{ccc}
\hline Usia (tahun) & Jumlah & \% \\
\hline$<1$ & 1 & 2,5 \\
$1-4$ & 0 & 0 \\
$5-14$ & 0 & 0 \\
$15-24$ & 2 & 5 \\
$25-44$ & 9 & 22,5 \\
$45-64$ & 17 & 42,5 \\
$\geq 65$ & 11 & 27,5 \\
Total & 40 & 100 \\
\hline
\end{tabular}

Tabel 3. Distribusi kandidosis intertriginosa menurut pekerjaan

\begin{tabular}{lcc}
\hline \multicolumn{1}{c}{ Pekerjaan } & Jumlah & \% \\
\hline Pegawai Negeri Sipil & 13 & 32,5 \\
Pegawai Swasta & 7 & 17,5 \\
Ibu Rumah Tangga & 10 & 25 \\
Pensiunan & 6 & 15 \\
Suster biara & 1 & 2,5 \\
Guru olahraga & 1 & 2,5 \\
Tidak bekerja & 2 & 5 \\
Total & 40 & 100 \\
\hline
\end{tabular}

Tabel 4 menunjukkan total jumlah yaitu 70. Hal ini dikarenakan hanya 19 pasien yang memiliki lesi pada 1 lokasi, selain itu 21 pasien lainnya memiliki lesi pada 2-3 lokasi. Dari keseluruhan lokasi didapati bahwa lipat paha merupakan lokasi lipatan kulit yang paling sering terjadi $(31,43 \%)$ diikuti oleh ketiak $(24,29 \%)$.

Tabel 4. Distribusi kandidosis intertriginosa menurut lokasi lipatan kulit

\begin{tabular}{lcc}
\hline \multicolumn{1}{c}{ Lokasi } & Jumlah & \% \\
\hline Ketiak & 17 & 24,29 \\
Lipat payudara & 10 & 14,28 \\
Lipat paha & 22 & 31,43 \\
Lipat perut & 9 & 12,86 \\
Sela jari kaki & 6 & 8,57 \\
Leher & 6 & 8,57 \\
Total & 70 & 100 \\
\hline
\end{tabular}

Tabel 5 menunjukkan jumlah keseluruhan pasien yang memiliki data mengenai faktor pencetus yaitu 24 pasien sedangkan 16 pasien lainnya tidak memiliki data yang lengkap. Berdasarkan data 24 pasien tersebut didapati bahwa berkeringat/ lingkungan lembab merupakan faktor pencetus terbesar kandidosis intertriginosa yaitu pada 13 pasien $(32,5 \%)$ diikuti oleh diabetes melitus (25\%).

Tabel 5. Distribusi kandidosis intertriginosa menurut faktor pencetus

\begin{tabular}{lcc}
\hline \multicolumn{1}{c}{ Faktor pencetus } & Jumlah & \% \\
\hline Diabetes melitus & 10 & 25 \\
Berkeringat/ & 13 & 32,5 \\
Lingkungan lembab & & \\
Obesitas & 1 & 2,5 \\
Tidak diketahui & 16 & 40 \\
Total & 40 & 100 \\
\hline
\end{tabular}

Tabel 6 memperlihatan bahwa obat yang paling sering diberikan pada pasien kandidosis intertriginosa ialah antifungi topikal $(65 \%)$ sedangkankombinasi obat kedua terbanyak yang diberikan ialah antifungi topikal dan antibiotik topikal $(27,5 \%)$.

Tabel 6. Distribusi kandidosis intertriginosa menurut terapi pengobatan

\begin{tabular}{lcc}
\hline \multicolumn{1}{c}{ Terapi obat } & Jumlah & \% \\
\hline Antifungi topikal & 26 & 65 \\
Antifungi topikal + & 11 & 27,5 \\
Antibiotik topikal & & \\
Antifungi topikal + & 1 & 2,5 \\
$\begin{array}{l}\text { Antibiotik sistemik } \\
\text { Antifungi sistemik + }\end{array}$ & 1 & 2,5 \\
$\begin{array}{l}\text { Antifungi topikal } \\
\text { Antifungi sistemik + } \\
\text { Antibiotik sistemik } \\
\text { Total }\end{array}$ & 1 & 2,5 \\
\hline
\end{tabular}

Keterangan:

Antifungi topikal: ketokonazole, mikonazole Antifungi sistemik:ketokonazole, itrakonazole Antibiotik topikal:asam fusidat, gentamisin Antibiotik sistemik:klindamisin, cefadroxil

\section{BAHASAN}

Penelitian ini dilakukan dengan menggunakan data rekam medik penderita kandidosis intertriginosa yang berobat di Poliklinik RSUP Prof. Dr. R. D. Kandou Manado periode Januari-Desember 2013. Berdasarkan hasil penelitian terdapat 40 pasien $(0,98 \%)$ didiagnosis kandidosis intertriginosa pada tahun 2013. Jika dibandingkan dengan penelitian yang dilakukan oleh Wowor et al. ${ }^{6}$ jumlah pasien 
kandidosis intertriginosa pada tahun 2012 tidak jauh berbeda dibanding pada tahun 2013 yaitu 37 pasien $(3,37 \%)$ dari 1096 keseluruhan pasien baru. Penurunan angka kejadian di tahun 2013 menunjukkan kemungkinan meningkatnya pemahaman dan kesadaran masyarakat akan kesehatan kulit khususnya penyakit kandidosis intertriginosa.

Pada distribusi penyakit menurut jenis kelamin, kasus kandidosis intertriginosa lebih banyak ditemukan pada perempuan (70\%) dibanding laki-laki (30\%). Dikaitkan dengan penelitian yang dilakukan di Irak $^{5}$ dan Wowor et al. ${ }^{6}$, pada perempuan lebih banyak didapati kasus kandidosis intertriginosa. Hal ini mungkin disebabkan oleh cara dan perilaku perempuan di kalangan masyarakat yaitu misalnya cara berpakaian yang ketat dan pakaian tertutup, ${ }^{7}$ serta penggunaan sepatu tertutup pada laki-laki maupun pada perempuan dengan bagian depan lebih kecil sehingga membuat lipatan-lipatan kulit menjadi lembab dan menghasilkan keringat yang berlebih dan rentan terhadap infeksi kandidosis intertriginosa. Lipatan payudara juga yang dimiliki perempuan merupakan lokasi lipatan kulit yang tertutup dan menghasilkan lingkungan yang lembab. ${ }^{10}$

Pada penelitian ini kandidosis intertriginosa paling banyak ditemukan pada kelompok usia 45-64 tahun (42,5\%), diikuti oleh usia $\geq 65$ tahun $(27,5 \%)$. Hal ini mungkin disebabkan pada orang tua atau usia lanjut terjadi penurunan imunitas atau status imunologik yang sudah tidak sempurna ${ }^{1}$, dimana terdapat penyakit yang rentan terhadap kandidosis misalnya diabetes melitus atau penyakit imunologik lainnya. Pada usia $<1$ tahun terdapat 1 pasien $(2,5 \%)$ dikarenakan penggunaan pampers yang menghasilkan aposisi lingkungan yang lembab. ${ }^{3}$

Pekerjaan dari pasien kandidosis intertriginosa melalui data penelitian didapatkan terbanyak sebagai Pegawai Negeri Sipil (PNS) yaitu sebanyak 13 pasien $(32,5 \%)$. Pada orang yang bekerja sebagai PNS, kemungkinan menggunakan pakaian yang tertutup sepanjang hari dan sepatu tertutup. Hal ini menyebabkan meningkatnya kelembaban dalam lipatan kulit dan dapat memicu peningkatan pertumbuhan jamur. $^{10}$ Pekerjaan kedua terbanyak yaitu ibu rumah tangga (IRT) sebesar 25\%. Sebagian besar IRT mengerjakan pekerjaan rumah, baik pada daerah basah (air) maupun kering. Kontaminasi kulit pada daerah basah yang berlebihan dapat menghasilkan lingkungan yang lembab sehingga mendukung untuk pertumbuhan jamur., 8

Distribusi lokasi lipatan yang terkena kandidosis intertriginosa mendapatkan hasil lipat paha $(31,43 \%)$ terbanyak, diikuti ketiak (24,29\%), dan lipat payudara $(14,28 \%)$. Hal ini disebabkan bagian lipat paha merupakan daerah yang paling tertutup serta sering terjadi gesekan kulit dan menghasilkan lingkungan lembab yang mendukung bertumbuhnya jamur Candida sehingga dapat menyebabkan terjadinya kandidosis intertriginosa. ${ }^{10}$ Lokasi kedua terbanyak yaitu pada ketiak. Hal ini disebabkan ketiak menghasilkan banyak keringat yang membuat daerah tersebut menjadi lembab dan menyebabkan pertumbuhan jamur Candida. ${ }^{8}$ Lokasi terbanyak selanjutnya yaitu pada lipatan payudara, yang sering menjadi lembab karena tertutup oleh pakaian., ${ }^{3,7}$ Pada lakilaki tidak memiliki lipatan payu dada kecuali laki-laki dengan obesitas.

Sebagian besar pasien memiliki lesi lebih dari satu lokasi lipatan kulit. Hal ini mungkin dikarenakan kurangnya kesadaran pasien untuk langsung memeriksakan diri ke dokter karena menganggap lesi yang timbul hanya merupakan lesi biasa yang akan hilang dengan sendirinya atau diobati dengan cara sendiri, sehingga setelah munculnya lesi di beberapa lokasi baru datang memeriksakan diri ke dokter.

Faktor pencetus kandidosis intertriginosa hanya didapatkan 24 dari 40 keseluruhan total pasien dan menunjukkan persentase terbesar yaitu pada pasien dengan berkeringat/lingkungan lembab (32,5\%). Hal ini mungkin disebabkan antara lain akibat penggunaan pakaian 
tertutup dan ketat serta sepatu yang tertutup. Dengan lingkungan seperti ini yaitu pada saat berkeringat lebih maka jamur Candida dapat bertumbuh dan berkembang. ${ }^{7}$ Persentase kedua tertinggi yaitu pada penyandang diabetes melitus $(25 \%)$. Hal ini disebabkan penyandang diabetes melitus ditandai dengan hiperglikemia yang disebabkan oleh defisiensi atau penurunan efektifitas insulin. Tingginya kadar glukosa darah dapat menyebabkan meningginya kadar glukosa kulit sehingga mempermudah timbulnya infeksi jamur. Infeksi jamur Candida albicans lebih mudah pada pasien dengan keadaan imunokompremise seperti diabetes melitus. ${ }^{12}$ Urutan ketiga yaitu obesitas dengan persentase $2,5 \%$. Obesitas sebagai salah satu faktor pencetus kandidosis intertriginosa didapatkan pada 1 pasien $(0,25 \%)$ dengan TB $178 \mathrm{~cm}$ dan $\mathrm{BB}$ $80 \mathrm{~kg}$ sehingga didapatkan IMT 27 (obese I). Pada 39 pasien lainnya tidak ada data tentang TB dan BB. Pada obesitas, tubuh menjadi lebih banyak berkeringat dan lembab serta terdapat banyak lipatanlipatan pada kulit. ${ }^{3}$

Terapi obat yang paling sering digunakan ialah antifungi topikal (ketokonazole, mikonazole) sebanyak 26 pasien $(65 \%)$. Terapi ini lebih dominan diberikan karena cukup untuk mengatasi infeksi jamur pada kulit. ${ }^{1,11}$ Pada beberapa pasien juga dikombinasikan dengan antibiotik topikal (asam fusidat dan gentamisin) $(27,5 \%)$. Pengobatan antibiotik dapat menghambat pertumbuhan dan membasmi mikroba jenis lain pada kulit yang terinfeksi serta menghilangkan penyebab infeksi sekunder. ${ }^{1,9}$

Dari jenis obat yang diberikan pada pasien, yang paling banyak digunakan yaitu antifungi topikal yaitu sebanyak 39 dari 40 pasien dan 2 pasien diberikan antifungi sistemik. Infeksi jamur dengan lesi yang tidak luas pada kulit dapat diberikan antifungi berupa topikal atau oles, sedangkan pemberian antifungi sistemik atau oral diberikan pada pasien dengan infeksi yang luas. ${ }^{13}$ Antibiotika topikal diberikan pada 11 pasien, karena pada pasien dengan kandidosis intertriginosa sering didapati terjadinya infeksi sekunder. ${ }^{1,11}$ Oleh sebab itu, kedua obat ini paling umum diberikan pada pasien kandidosis intertriginosa.

\section{SIMPULAN}

Berdasarkan hasil penelitian dan bahasan didapatkan angka kejadian kandidosis intertriginosa 0,98\% dari 4099 pasien di Poliklinik Kulit dan Kelamin RSUP Prof. Dr. R.D. Kandou Manado tahun 2013.

Kasus kandidosis intertriginosa terbanyak pada perempuan, kelompok usia 45-64 tahun, pekerjaan sebagai PNS, lokasi lipat paha, faktor pencetus berkeringat/ lingkungan lembab, antifungi azol topikal, dan kombinasi obat antifungi topikal dan antibiotik topikal.

\section{SARAN}

Perlu meningkatkan dan memperjelas kelengkapan dalam pengisian status pasien termasuk kelengkapan status faktor risiko sehingga dapat mempermudah penelitian di kemudian hari.

\section{DAFTAR PUSTAKA}

1. Kuswadji. Kandidosis. In: Djuanda A, Hamzah M, Aisah S, editors. Ilmu Penyakit Kulit dan Kelamin (6th ed). Jakarta: FKUI, 2015; p. 106-9.

2. Siregar RS. Mikosis intermediet: Kandidiasis. In: Penyakit Jamur Kulit (2nd ed). Jakarta, 2005; p. 44-60.

3. Brown RG, Burns T. Infeksi jamur. In: Safitri A, editor, Lectures Notes: Dermatologi (8th ed). Jakarta, 2005; p. 38-40.

4. Scott SD. Cutaneous candidiasis. 2006 [cited 2015 Okt 1]. Available from: http://www.medlineplus.com

5. Hasan ASH, Al-Duliami AA, Al-Azawi NS. The rate of cutaneous candidiasis in patients with skin mycoses in Baquba/Diyala Province Iraq. Iraq $\mathbf{J}$ Comm Med. 2008;3:245-5.

\section{Wowor SR, Pandaleke Herry EJ, Kapantow} MG. Profil kandidosis intertriginosa di Poliklinik Kulit dan Kelamin RSUP Prof. Dr. R. D. Kandou periode Januari-Desember 2012. eCl. 2014;2(1). 
7. Kondo RV, Garg A. Yeast infection: Candidiasis, Tinea (Pityriasis) Versicolor, and Malassezia (Pityrosporum) Folliculitis. In: Goldsmith LA, Katz SI, Gilchrest BA, Paller AS, Leffell DJ, Wolf K, editors. Fitzpatrick's Dermatology in General Medicine (8th ed). USA: McGraw-Hill, 2012; p. 2301-7.

8. James WD, Berger TG, Elston DM. Disease Resulting from fungi and yeasts. In: Andrew's Disease of the Skin Clinical Dermatology (10th ed). Saunders Elsevier, 2006; p. 308-11.

9. Scheinfeld NS, Lambiase MC, Lehman DS, Allan JM. Cutaneous Candidiasis. 2015 April 29 [cited 2015 Sept 25]. Available from: http: //emedicine. medscape.com/article/213853overview\#a7

10. Dellavalle RP, Rosen T. Candidal intertrigo.
2015 [cited 2015 Okt 7]. Available from: http: //www. uptodate.com/contents/candidalintertrigo\#H4

11. Wolff K, Johnson RA, Saavedra AP. Fungal infection of the skin, hair, and nails. In: Fitzpatrick's Color Atlas and Synopsis of Clinical Dermatology (7th ed). Mc Graw-Hill, 2013; p. 591-3.

12. Octavia PA, Ramona F, Pramuningtyas R. Hubungan penyakit diabetes melitus dengan kejadian kandidiasis kutis di RSUP Dr. Soeradji Tirtonegoro Klaten [Skripsi]. Surakarta: Universitas Muhammaduyag; 2014.

13. Winata SM. Obat antifungal. 2014 [cited 17 Januari 2016]. Available from: http://www.kerja-obat-antifungalscribd.com. 